\title{
Goal and Source: Their Syntactic and Semantic Asymmetry
}

\author{
SEUNGHO NAM \\ Seoul National University
}

\section{Introduction}

This paper investigates the syntactic and semantic difference between two types of directional PPs - (i) Goal locatives (e.g., into the store) and (ii) Source locatives (e.g., from the store). Their contrastive syntactic behavior is identified in various constructions, and we account for the contrast by assigning them two distinct underlying base positions. Further, we argue that their systematic semantic differences are predicted by their semantic scope in event structure.

Jackendoff $(1983,1990)$ does not take thematic roles like Source and Goal as grammatical primitives, and the notions are defined in his lexical conceptual structure of event. Thus in Jackendoff (1990), Goal and Source are defined as the arguments of Path-functions, [Path TO ([Place ... ])] and [Path FROM ([Place ... ])], respectively. Prepositions like to, into and onto typically take a Goal argument, and from, from under, from behind, and off can take a Source argument.

The paper is organized as follows: Section 1 illustrates the Goal-Source asymmetry in syntax, specifically in the structures of Preposition Incorporation, Prepositional/Pseudo Passives, PP-dislocation and locative alternations. Section 2 shows the semantic contrast between Goal and Source PPs with respect to adverbial modification and aspectual composition. Section 3 proposes two distinct underlying base positions of Goal and Source locatives, and accounts for the syntactic and semantic contrast in terms of more fine-grained event structure. Further, we propose a set of mapping rules which link the locative PPs in event structure with their syntactic positions.

\footnotetext{
1 Koopman (1997) proposes two locative functional heads in Dutch, i.e., 'Place' for nondirectional locatives, and 'Path' for directions ones. Thus Path Phrase may contain a Place Phrase. Kracht (2002) also identifies directional and non-directional senses in terms of 'Modalizer' and 'Localizer,' respectively. Maienborn (2001), dealing with only nondirectional locatives in German, proposes three syntactic base positions: (i) "frame-setting modifiers"; (ii) "external locatives", and "internal locatives."
} 


\section{Goal-Source Asymmetry in Syntax \\ 1.1. Preposition Incorporation}

Preposition incorporation (PI, henceforth) reveals the Goal-Source contrast as well as the contrast between directional vs. non-directional locatives. Baker (1988) illustrates that the PPs of Dative and Goal are most common in PI, and claims that the arguments associated with the applicatives are theta-marked ones, i.e., "inner locatives" in the sense of Hornstein and Weinberg (1981). The following data (1) in Kinyarwanda and (2) in Chichewa are from Kimenyi (1980), and Baker (1988), respectively.
a. Abaana b-iica-ye ku meeza children SP-sit-ASP on table
b. Abaana b-iica-ye-ho ameeza children SP-sit-ASP-on table
'The children are sitting on the table.'
a. Ndi-na-tumiz-a
chipanda cha mowa kwa mfumu 1sS-PAST-send-ASP calabash of beer to chief 'I sent a calabash of beer to the chief.' 1sS-PAST-send-to-ASP chief calabash of beer 'I sent the chief a calabash of beer.'
b. Ndi-na-tumiz-ir-a mfumu chipanda cha mowa

The verbal complex in (1b) contains an applicative suffix -ho 'on' instead of the lexical preposition $k u$ 'on' in (1a). (2a) has a lexical preposition $k w a$ 'to', but in (2b) the applicative suffix -ir 'to' (Goal) is incorporated into the verbal complex. Baker (1988) and Kimenyi (1980), however, illustrate few source locatives. ${ }^{2}$

Koopman (1997) shows that Dutch postpositions and particles can incorporate to $\mathrm{V}$ deriving a directional interpretation, but prepositions cannot due to their nondirectional reading. A prepositional PP may derive a goal directional reading, if it is selected by a motion verb. Thus (3a) has an incorporated (directional) preposition in between the auxiliary verb is and the main verb geklommen 'climb', and (3b) has a directional postposition door 'through' incorporated to $\mathrm{V}$ after the auxiliary verb is 'be.'

$$
\begin{aligned}
& \text { a. omdat zij de boom is in geklommen } \\
& \text { because she the tree is in climbed } \\
& \text { 'because they climbed into the tree' }
\end{aligned}
$$

\footnotetext{
${ }^{2}$ The following is the sole example of PI with a Source argument in Baker (1988:240).
(i) Kambuku a-na-b-er-a mkango njinga.
leopard SP-PAST-steal-APPL-ASP lion bicycle
'The leopard stole the bicycle from the lion.'

Baker reports that (i) also has a Benefactive reading: i.e., 'The leopard stole the bicycle for the lion.' But the Source reading obtains since the Source is a true argument of the verb 'to steal.'
} 
b. omdat zij het bos is door gelopen because she the forest is through walked 'because she walked through the forest'

Further, unlike Goal directional PPs, Dutch Source directional PPs do not allow PI. Thus, the goal type particle heen may be incorporated to V as in (4a), but the source type particle vandaan in (4b) may not.

(4) a. dat zij de jas over de stoel hebben heen gelegd that they the coat over the chair have prt put 'that they laid the coat over the chair'

b. dat dit book (van) onder het bed is (?*vandaan) gekomen that this book from under the bed is from come. 'that this book came from under the bed'

Notice that van 'from' in (4b) is a preposition. The source PPs with van, however, can be dislocated by pied-piping and PP-over-V movement, while goal type PPs cannot. (See Koopman (1997) for examples illustrating this point.)

Munro (2000) shows that some verbs in Choctaw and Chickasaw can occur with more than one applicative prefix. She says "there is a strong constraint against verbs with a total of more than four arguments". Munro (2000) notes that the order of the prefixes in the combinations, specifically in Chickasaw, is subject to the following constraint: Non-directional prefixes precede Source ones which precede Goal-directional ones. This applicative prefix ordering suggests that the different locative argument/adjuncts occupy different syntactic positions, and further they modify different semantic domains.

\subsection{Prepositional (Pseudo) Passives}

Prepositional passives show a similar contrast between Goal and Source locatives. (5-7) below illustrate active-passive pairs, where the passive sentences have a stranded preposition, and its object NP is promoted to the subject position. When a PP denotes a benefactive (5), goal (6), or comitative (7), its object NP is allowed to be the passive subject. The data are quoted from Couper-Kuhlen (1979).

(5) a. His surviving brother provided for John's widow. [benefactive]

b. John's widow was provided for by his surviving brother.

(6) a. Several magistrates spoke to him. [goal]

b. He was spoken to by several magistrates.

(7) a. Anyone cannot room with Martha. [comitative]

b. Martha can't be roomed with by anyone.

When the PP denotes a circumstantial location or source, however, its NP is 
hardly found in the passive subject position. Thus, the (a)-sentences with a goal locative in (8-10) are acceptable, whereas the (b)-sentences with a source locative sound bad.

(8) a. The store can be run to in a matter of minutes ... [goal]

b. *The store can be run from in a matter of minutes ... [source]

(9) a. If the boat is jumped into ... it may capsize. [goal]

b. *If the boat is jumped from ... it may capsize. [source]

(10) a. The house was moved into three weeks ago ... [goal]

b. ?*The house was moved from three weeks ago ... [source]

Notice that the following minimal pairs show the same contrast in between directional and non-directional uses of the prepositions.

(11) a. The road could be driven across only at great risk ...

b. *The road could be played across only at great risk ...

(12) a. The gate mustn't be gone beyond ...

b. *The gate mustn't be played beyond ...

\subsection{Movement and Ordering}

We have other syntactic evidence revealing the contrast between Source and Goal PPs: That is, Source PPs can be easily dislocated, while Goal PPs cannot. The Source PP from Los Angeles in (13) can move to the front by Topicalization, whereas the Goal PP to Chicago resists movement. This suggests that the Goal PP behaves more like a true complement of the verb send than the Source PP does.

(13) a. From Los Angeles, John sent the letter to Chicago.

b. ??To Chicago, John sent the letter from Los Angeles.

Now we note that a Source PP is more ready to scramble with a temporal/aspectual PP. Thus, the PP from the library in (14) can move over the durative adverbial for ten minutes, but the Goal PP to the library in (15) is not allowed to move over the time-frame adverbial in ten minutes.

(14) a. He ran from the library for ten minutes.

b. He ran for ten minutes from the library.

(15) a. He ran to the library in ten minutes.

b. ??He ran in ten minutes to the library.

Goal PPs, combining with a transitive verb, always specify the location or the 
movement of the Theme argument, i.e., the argument in direct object position. So (16a) entails that 'Mary was in the garden' and (16b) entails that 'the hay moved onto the truck.'

(16) a. John saw Mary in the garden.

b. John loaded the hay onto the truck.

If the verbs take a Source PP, however, it may denote either the location of the subject argument or the location of the object argument. That is, from the rooftop in (17a) refers to the location of John (the subject), and from the ground in (17b) refers to the source location of the hay. In other words, we can say that the Source PP from the rooftop is 'subject-oriented' and the other PPs in $(17 \mathrm{a}, \mathrm{b})$ are 'objectoriented.'

(17) a. John saw Mary in the garden from the rooftop.

b. John loaded the hay onto the truck from the ground.

We note here that the PPs are not free in ordering: that is, if an object is followed by an object-oriented PP and a subject-oriented PP in English, the former always precedes the latter. Therefore, the two PPs in (17a) cannot scramble as in (18a), but those in (17b) can as in (18b). (18a) may have a reading where 'the rooftop was in the garden,' which is not the intended reading of (17a).

(18) a. *John saw Mary from the rooftop in the garden.

b. ?John loaded the hay from the ground onto the truck.

We have seen that Goal PPs are always oriented to the object/theme argument but Source PPs may be oriented to the subject argument. The data also show that two locative PPs oriented to the same argument (e.g., Theme) can change their positions, but those oriented to different arguments cannot.

\subsection{Locative Alternations}

English and many other languages allow locative alternations like the following:

(19) a. Bees are swarming in the garden. $\Leftrightarrow$

b. The garden is swarming with bees.

(20) a. John sprayed paint on the wall. $\Leftrightarrow$

b. John sprayed the wall with paint.

(21) a. The woman embroidered flowers on the jacket. $\Leftrightarrow$

b. The woman embroidered the jacket with flowers. 
These alternation patterns have been attested and well described in many languages. In (19a), the intransitive verb swarm takes a locative PP in the garden, but the same location the garden shows up as a subject in (19b). (20) and (21) illustrate more alternation patterns between two transitive structures: one of the structures takes a locative PP, which turns into a direct object in the other structure. $^{3}$

Locative PPs involved in such alternations are mostly Goal-type locatives, i.e., the nouns of the PPs denote a goal/result location of the relevant argument typically a Theme. Thus, (19-21) entail 'bees are in the garden,' 'paint ends up being on the wall,' and 'flowers come to exist on the jacket,' respectively. Syntactically, the locative arguments are promoted to subject in (19) or to direct object in (20-21), and we claim that the promotion should be subject to a syntactic constraint: that is, only V'-internal/inner locatives can be promoted by locative alternation. In a more general context, we claim that V-modifiers like Goal-type PPs allow locative alternation while VP-adjuncts like Source and Path-type PPs hardly do. Further, non-directional PPs - higher VP-adjuncts - do not participate in locative alternation, either.

\section{Goal and Source in Event Structure}

\subsection{Adverbial Modification and Locative PPs in Event Structure}

We argue that the various modes of locative modification require a more finegrained event structure. Alsina (1999), Tenny (2000), and Travis (2000) identify "outer" (causing) event and "inner" (result/core) event. Pustejovsky (1995), Eckardt (1998) and Ernst (1998) account for (scopally) ambiguous adverbial modification in terms of event structure.

(22) a. Harry departed the room rudely.

b. The police quickly arrested John.

c. John clumsily spilled the beans.

The three sentences above all have an adverb that gives a manner reading, thus (22a) has a reading where Harry might have interrupted others by banging the door, for example. We can easily get such manner readings in $(22 b, c)$, too. Further, the sentences have another reading where the adverbs modify the whole event, i.e., they are predicated of the whole event. Thus (22a) means that 'the event of Harry's departing the room was rude'. Pustejovsky (1991) represents the ambiguous readings in a parallel event structure as the following.

\footnotetext{
3 There have been many proposals to account for these locative alternations. Pustejovsky (1991, 1995) accounts for the transitive alternations like the following in terms of "HEAD" underspecification of event structure.

(i) The enemy sank the boat.

(ii) The boat sank.

Further, Lee et al. (1998) and Alsina (1999) extend the underspecification method to locative and causative alternations.
} 
(23) Pustejovsky (1991): Harry departed the room rudely.

a. / E0:Transition

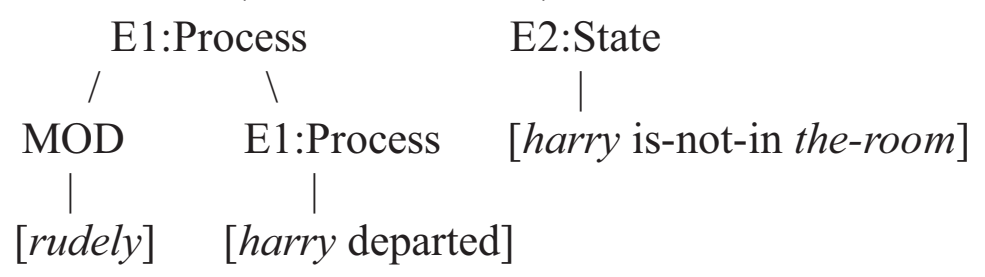

b.

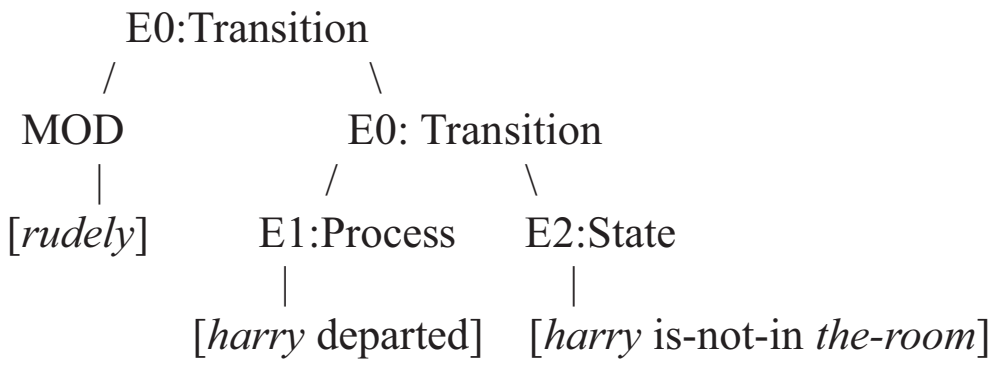

(23a) represents the manner reading of rudely in (22a), and (23b) the other reading of (22a) where the modifier (MOD) scopes over the whole event E0.

Let us now see another adverb again, a so called "repetitive" adverb, which can be interpreted ambiguously in the following sentences. They are quoted from Dowty (1979).

(24) a. John closed the door again.

b. John fell asleep during the lecture, but Mary quickly shook him awake again.

c. The book had fallen down, but John put it on the shelf again.

According to Dowty (1979), (24a) above is ambiguous: (i) the event of John's closing the door is assumed to have occurred previously, and (ii) the state of the door being closed is assumed to have existed previously, i.e., not necessarily as a result of John's action. In other words, the first reading indicates that the whole event is repeated, while the second reading means that only the result state of being closed is repeated. Tenny (2000) calls the first reading 'repetitive', and the second reading 'restitutive'. We have rather clear ambiguity in $(24 b, c)$.

This type of ambiguity in adverbial modification - rudely, quickly, again naturally suggests that each of the adverbs can be generated in two distinct base positions in extended VP structures: i.e., VP-internal subject structure of Koopman \& Sportiche (1991); VP-shell structure of Larson (1988); and VP in Lsyntax of Hale and Keyser (1993, 2002), among others. Cinque (1999) has proposed various underlying positions for adverbs in his "universal hierarchy of functional head projections," and he assigns two underlying positions to an adverb like again or quickly. Thus, again is generated under either Asp-repetitive(I) or 
Asp-repetitive(II), and quickly under Asp-celerative(I) or Asp-celerative(II).

Now let us consider how Goal and Source PPs interact with again. Their syntactic behavior we discussed in section 2 suggests that Goal PPs should be syntactically much closer to the verb than Source PPs are. Now considering their semantic interaction with again, we claim that Goal PPs constitute a core event (i.e., result state) whereas source PPs do not. Therefore, again allows a restitutive (narrow scope) reading with a Goal PP but not with a Source PP.

a. John drove to New York again. [ambiguous]

b. John drove from New York again. [repetitive reading only]

(26) a. John sent the book to New York again. [ambiguous]

b. John sent the book from New York again. [repetitive reading only]

Again in (25a) gives two readings: (i) repetitive reading - 'the event of John's driving to New York is repeated', and (ii) restitutive reading - 'the state of John's being at New York is resumed/restituted'. The second reading does not imply that John drove to New York previously. (25b) however, does not give a restitutive reading, since the sentence lacks an expression that may denote a result state. The same contrast holds for (26a) and (26b). We will see shortly that the semantic contrast between Source and Goal PPs can be accounted for by assigning them two independent semantic scopes in the event structure.

\subsection{Aspectual Division}

Cinque (1999) and Travis (2000) identify (at least) two aspectual domains in syntax, which Tenny (2000) labels "higher/viewpoint aspect" and "middle/situation aspect". We argue that Source-type PPs scope over the whole situation aspect, so they, unlike Goal PPs, do not shift the aspectual character (situation aspect) of the inner event denoted by the lower VP.

a. Mary ran (for ten minutes $/ *$ in ten minutes).

b. Mary ran to the store (in ten minutes $/ *$ for ten minutes).

c. He ran from the library (for ten minutes $/ *$ in ten minutes).

(27a) denotes an atelic activity, which does not normally go with a time-frame adverbial like in ten minutes. When a Goal PP combines with the verb, however, it changes the aspectual character of the verb, so the sentence denotes a telic event of accomplishment. Thus, (27b) is fine with a time-frame adverbial but it is bad with a durative adverbial for ten minutes. Unlike Goal PPs, the Source PP from the library does not change the aspectual character of the verb, so (27c) behaves in the same way as (27a) does. This contrast between Goal and Source PPs on aspectual shift suggests that the Goal PPs should be treated just like an internal argument which participate in aspectual composition. The incremental (or quantized) theme discussed in Tenny (1994), Verkuyl (1993), and Krifka (1995) is an 
internal argument which determines the aspectual character of the VP.

Let us assume that, in a fine-grained VP internal structure, Asp-head separates the lower and the higher VPs. Then, we propose that Goal PPs are generated under the AspP while Source PPs are generated in a position higher than the AspP. We will implement the asymmetry in the extended VP structure and event structure proposed shortly in section 3 .

\subsection{Non-locative Source PPs}

Source PPs headed by from in English often give a non-locative reading, thus the from PPs below refer to Cause in (28-29) and Agent in (30).

a. Harry died from AIDS complications. [Cause]

b. We have reports of death from AIDS complications.

a. No damage was caused from the shooting. [Cause]

b. Their estimates indicate damage from the freeze totals $\$ 385$ million.

a. We have been promised from the top in Moscow that ... [Agent]

b. ... challenge/support/donation/help/approval from the company

The Source PPs in (28) and (29) both denote a state or an event which caused a result state. In (28a) Harry's state of being under AIDS complications caused his death, and in (29a) the shooting event caused no damage. We also find in (28b) and (29b) the same semantic relation between a predicative noun (reports and damage) and a Source PP. Thus the sentences take these PPs as composing a causing sub-event of their event structures. Further, (30a) shows that a Source PP can denote an Agent of passive sentences, and such Agent reading can be obtained in nominal constructions in (30b). If an Agent argument shows up in a complex event of a transitive verb, it does not play a role in its result state. Instead the Agent role is essential in its causing sub-event. We will see that these nonlocative readings of Source PPs can be properly represented in the event structures proposed in 3.2.

\section{Proposal: Base Positions of Locative PPs and their Semantic Scope}

Here we adopt the extended VP structure of Hale and Keyser (1993), and propose two separate base positions where Goal PPs and Source PPs are generated. Further, extending Pustejovsky's (1991, 1995) event structure, we represent their semantic scope in the event structure. A complex event contains at least two conjoined sub-events: one is typically a Process which denotes a 'causing' subevent, and the other is a State which denotes a 'result' state. In the event structures we illustrate in this section, the Process sub-event is assumed to temporally precede or overlap with the State sub-event.

\subsection{Goal PPs: Internal Locatives}

Let us first consider Goal PPs like those in (31): the Goal PPs $\left(\mathrm{PP}_{\mathrm{G}}\right)$ are generated under the lower VP, where a Goal PP combines with V2 to form V2' as shown in 
(32). V2' may contain an internal argument (Theme).

(31) a. John swam to the boat.

b. Marta loaded the hay onto the truck.

$$
\left[\mathrm{vP} 1 \mathrm{DP} 1\left[\mathrm{v} 1, \mathrm{~V} 1 \ldots\left[\mathrm{vP} 2 \ldots\left[\mathrm{v} 2,(\mathrm{DP} 2) \mathrm{V} 2 \ldots \mathrm{PP}_{\mathrm{G}}\right]\right]\right]\right]
$$

As we have seen in section 2, Goal PPs are interpreted as composing a result state. A Goal PP generated under the lower VP specifies the final location of Theme argument, which shows up as a direct object of a transitive verb or as a subject of an intransitive verb. Then the result state will be composed of the Theme and the Goal. Thus, we represent the event structure of (31a) as (33) below. The lexical verb swim does not denote a complex event by itself, but the Goal PP extends the simplex event (E1) to a complex one with a result state (E2). (31a) entails the result state (E2) 'John was at the boat'.

John swam to the boat.

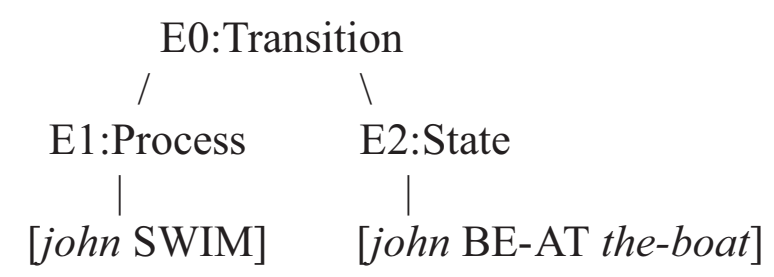

We take the event structure (33) as a semantic structure which can be mapped to its syntactic VP structure of (32). Thus, we characterize the mapping as follows:

(34) Mapping-1: PPs constituting a result state are generated in the lower VP.

Notice that the Goal PP is then treated exactly like a resultative phrase, which evidently forms a result state in the following sentences.

(35) a. The potter baked the clay hard.

b. She cooked the food brown.

c. The dog barked the neighbors awake.

That is, each of the resultative phrases in (35) denotes a predicate of a result state, and they are generated under the lower VP. As we discussed in 2.1, again modifies a result state to give a "restitutive" reading, then due to (34) Mapping-1 the adverb is also generated under the lower VP.

\subsection{Source PPs: Intermediate Locatives}

Now let us consider the Source PPs in (36) below: We claim that the Source PP 
adjuncts $\left(\mathrm{PP}_{\mathrm{S}}\right)$ should be generated under the higher VP, so they scope over V1' containing the lower VP2 as shown in (37).

(36) a. John swam to the boat from the beach.

b. Marta sent the book from Chicago.

$$
\left[\mathrm{vP} 1 \mathrm{DP} 1 \ldots \mathrm{PP}_{\mathrm{S}} \quad[\mathrm{v} 1, \mathrm{~V} 1 \ldots[\mathrm{vP} 2 \ldots[\mathrm{v} 2,(\mathrm{DP} 2) \mathrm{V} 2 \ldots]]]\right]
$$

As we have seen in 2, the Source PPs do not compose the result state, so they do not affect the aspectual character of the verb. The Source PP in (36a) indicates the initial point of John's movement, so it is represented as a modifier of the causing event in (38) below. ${ }^{4}$ (39) states the mapping relation between the semantic structure of (38) and the syntactic configuration of (37).

(38) John swam to the boat from the beach.

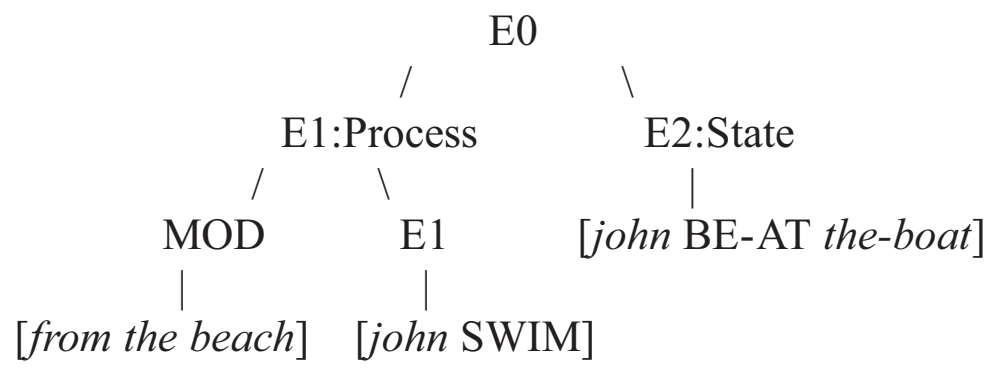

(39) Mapping-2: PPs modifying a causing event are generated under the higher VP.

As we have seen in 2, there are other adverbials that modify the causing subevent (Process): e.g., subject-oriented adverbials like reluctantly in (40a), temporal (frame) adverbials like in an hour in (40b), and manner adverbials like clumsily in (40c). We claim that the adverbials, just like Source PPs, are also generated under the higher VP.

(40) a. The man reluctantly sold the car to me.

b. John painted a picture in an hour.

c. The boy clumsily spilled the beans over the floor.

Some verbs of removing like empty, remove, clear and wipe take a Source PP as a core argument as in (41). Then the PP should be generated in the lower V2' just like Goal PPs.

\footnotetext{
4 Again, the meaning of the verb determines what entity is located by the source PP: (36a) implies John's change of location, and (36b) implies the book's change of location.
} 
(41) a. They emptied water from the tank.

b. He wiped crumbs off the table.

Source PPs may have a non-locative reading, so we noted in 2.3 that the PP from AIDS complications in (42) below denotes the cause of Harry's death.

(42) Harry died from AIDS complications.

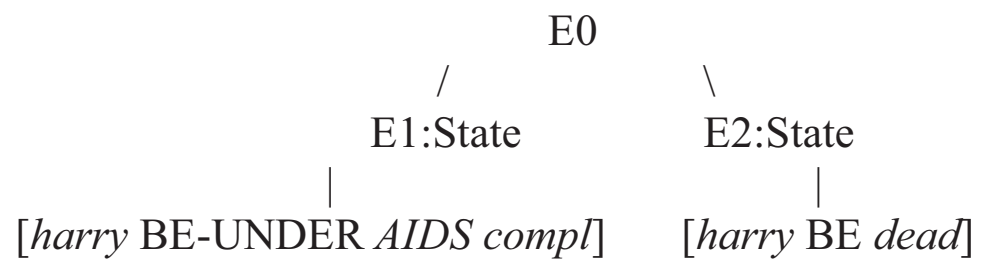

In 2.1, we noted that again and quickly may be ambiguous with respect to their semantic scope. Thus the adverbs in (43) below can modify either a subevent (result state or process) or the whole event. When they modify the whole event, the PPs should be generated adjoined to the higher VP due to (39). Thus we can represent the ambiguity of again as in the following:

(43) a. John drove to New York again.

b. The police quickly arrested John.

(44) a. John drove to New York again. [again in restitutive reading]

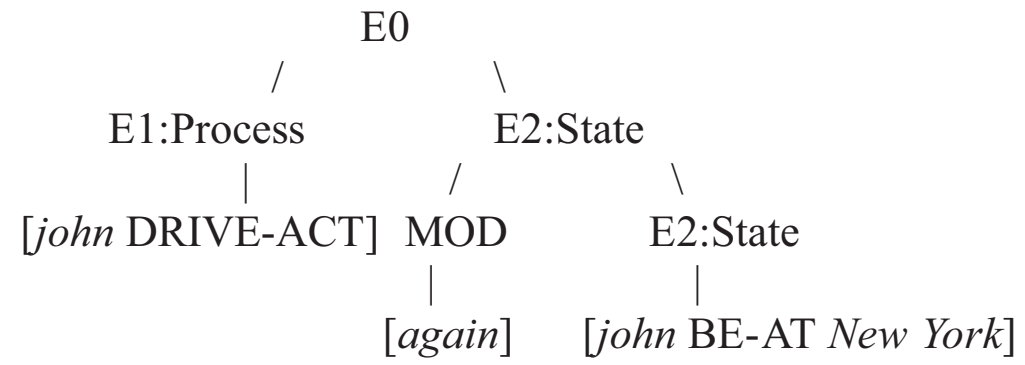

b. John drove to New York again. [again in repetitive reading]

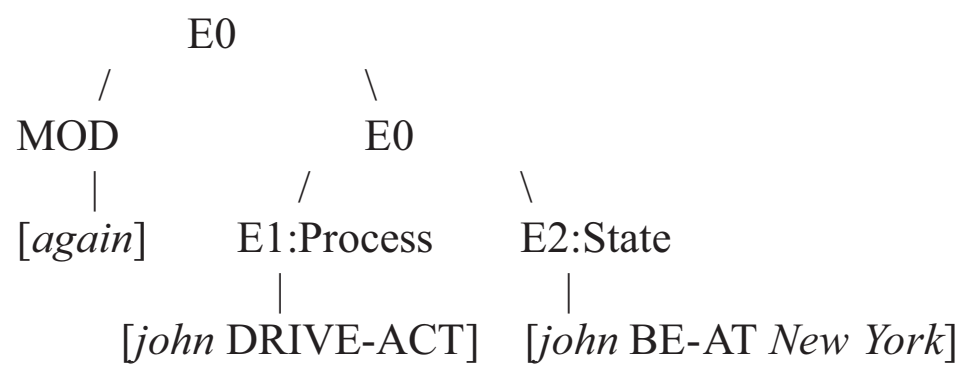

\section{4. $\quad$ Concluding Remarks}

Based on the extended VP-structure of Hale and Keyser (1993) and the event 
structure of Pustejovsky (1991), we proposed a more explicit mapping between syntax and semantics of directional PPs - particularly Goal and Source PPs. Thus, we argued that goal locative PPs are generated under the lower VP and compose a result state sub-event, and source locative PPs are generated under the higher VP and modify a process sub-event. The syntactic behavior of Source and Goal PPs discussed in section 2 suggests in general that Goal PPs have more integrity with the verb than Source PPs do. We illustrated their contrast in terms of Preposition Incorporation (1.1), Pseudo-passive (1.2), Movement (1.3), and Locative Alternation (1.4). The semantics of Source and Goal PPs is characterized largely in terms of scope: that is, their scope properties in event structures are supported by the ambiguous readings of various adverbs (like again, quickly, and rudely) (2.1), and further by the clear contrast in their contribution to aspectual interpretation (2.2).

We expect that the proposed account will be supported more firmly if we explore their syntactic and semantic behavior in relation to the wider range of PPs and adverbials. We have not dealt with intensional locative PPs (e.g., framesetting, perspectival, and speech act oriented locatives) or symmetric Path-type PPs (e.g., through the tunnel and over the bridge). But these PPs should be included in further research on locative modification.

\section{References}

Alsina, A. 1999. On the representation of event structure. In Tara Mohanan and Lionel Wee (eds.) Grammatical Semantics - Evidence for Structure in Meaning, 77-122. Stanford, CA: CSLI.

Baker, M. 1988. Incorporation: A Theory of Grammatical Function Changing. Chicago: University of Chicago Press.

Cinque, G. 1999. Adverbs and Functional Heads: A Cross-Linguistic Perspective. Oxford: Oxford University Press.

Couper-Kuhlen, E. 1979. The Prepositional Passive in English. Tuebingen: Max Niemeyer Verlag.

Dowty, D. 1979. Word Meaning and Montague Grammar. Dordrecht: Reidel.

Eckardt, R. 1998. Adverbs, Events, and Other Things: Issues in the Semantics of Manner Adverbs. Tuebingen: Max Niemeyer Verlag.

Ernst, T. 1998. Scope Based Adjunct Licensing. NELS 28. Amherst: GLSA.

Hale, K. and S. J. Keyser 1993. On argument structure and the lexical expression of syntactic relations. In K. Hale and S. J. Keyser (eds.) The View from Building 20. Cambridge, MA: The MIT Press.

Hale, K. and S. J. Keyser 2002. Prolegomenon to a Theory of Argument Structure. Linguistic Inquiry Monograph 39. Cambridge, MA: The MIT Press.

Hornstein, N. and A. Weinberg. 1981. Case Theory and Preposition Stranding. Linguistic Inquiry 12: 55-92.

Jackendoff, R. 1983. Semantics and Cognition. Cambridge, MA: The MIT Press. Jackendoff, R. 1990. Semantic Structures. Cambridge, MA: The MIT Press. 
Kimenyi, A. 1980. A Relational Grammar of Kinyarwanda. Berkeley, CA: University of California Press.

Koopman, H. 1997. Prepositions, postpositions, circumpositions and particles: The structure of Dutch PPs. Ms., University of California, Los Angeles.

Koopman, H. and D. Sportiche. 1991. The Position of Subjects. Lingua 85: 211258.

Kracht, M. 2002. On the Semantics of Locatives. Linguistics and Philosophy 25: 157-232.

Krifka, Manfred. 1992. Thematic Relations as Links between Nominal Reference and Temporal Constitution. In I. Sag and A. Szabolcsi (eds.) Lexical Matters. Stanford, CA: CSLI.

Larson, R. 1988. On the double object construction. Linguistic Inquiry 19: 335392.

Lee, C., S. Nam, and B. Kang 1998. Lexical semantic structure for predicates in Korean. In J. Bos and P. Buitelaar (eds.) Lexical Semantics in Context. U. of Saarbruecken, Germany: European Summer School in Logic, Language and Information.

Maienborn, C. 2001. On the position and interpretation of locative modifiers. Natural Language Semantics 9: 191-240.

Munro, P. 2000. The leaky grammar of the Chickasaw applicatives. In Arika Okrent and John P. Boyle (eds.) Proceedings of the Thirty-Sixth Annual Meeting of the Chicago Linguistic Society, Main Session (CLS 36-1), 285-310. Chicago: Chicago Linguistic Society.

Nam, S. 1995. Semantics of locative prepositional phrases in English. PhD dissertation, University of California, Los Angeles.

Pustejovsky, J. 1991. The syntax of event structure. Cognition 41: 47-81.

Pustejovsky, J. 1995. The Generative Lexicon. Cambridge, MA: The MIT Press.

Pustejovsky, J. and C. Tenny (eds.). 2000. Events as Grammatical Objects. Stanford, CA: CSLI.

Tenny, C. 1994. Aspectual Roles and the Syntax-Semantics Interface. Dordrecht: Kluwer Academic Press.

Tenny, C. 2000. Core events and adverbial modification. In J. Pustejovsky \& C. Tenny (eds.), 285-334.

Travis, L. 2000. Event Structure in Syntax. In J. Pustejovsky \& C. Tenny (eds.), 145-185.

Verkuyl, H. 1993. A Theory of Aspectuality. Cambridge University Press.

Seungho Nam

Linguistics Department

Seoul National University

Seoul, 151-742

Republic of Korea

nam@snu.ac.kr 